\title{
Author Correction: Metabolic and immunomodulatory control of type 1 diabetes via orally delivered bile-acid-polymer nanocarriers of insulin or rapamycin
}

Jung Seok Lee DD, Patrick Han (D), Rabib Chaudhury, Shihan Khan, Sean Bickerton (D), Michael D. McHugh, Hyun Bong Park, Alyssa L. Siefert, Gerald Rea, José M. Carballido DD, David A. Horwitz, Jason Criscione, Karlo Perica, Robert Samstein, Ragy Ragheb, Dongin Kim and Tarek M. Fahmy iD

Correction to: Nature Biomedical Engineering https://doi.org/10.1038/s41551-021-00791-0, published online 6 October 2021.

In the version of this Article initially published, there was an error in the list of author names. Ragy Ragheb's last name was misspelt in the original as Rageb. The error has been corrected in the online version of the paper.

Published online: 4 November 2021

https://doi.org/10.1038/s41551-021-00828-4

() The Author(s), under exclusive licence to Springer Nature Limited 2021 